\title{
Assessment of Extension Agents' Perception of Mobile Phone Usage for Communication with Farmers in Edo South of Edo State, Nigeria
}

\author{
S. O. E. Alakpa ${ }^{1, *}$, S. O. Afolabi ${ }^{2}$, I. J. Ighalo ${ }^{1}$ \\ ${ }^{1}$ Department of Agricultural Economics and Agricultural Extension, Faculty of Agriculture and Agricultural Technology, \\ Benson Idahosa University, Nigeria \\ ${ }^{2}$ Samuel Adegboyega University, Nigeria
}

Copyright $\bigcirc 2019$ by authors, all rights reserved. Authors agree that this article remains permanently open access under the terms of the Creative Commons Attribution License 4.0 International License

\begin{abstract}
The use of mobile phones as means of communication between the extension agents and local farmers in Edo South was examined to determine the perception of the extension agents on its effectiveness. Fifty-one (51) respondents were obtained through random sampling using questionnaires to obtain relevant information in the two local government areas; Ovia North East and Ovia South West selected for the study. The result obtained indicated that male extension agents were in majority $(72.5 \%), 54.9 \%$ of the sampled population above 45 years of age and $58.8 \%$ possessed $16-20$ years working experience. Phone calls and short message service (SMS) were found appropriate for agricultural information dissemination. Significant and positive relationships were established between the working experience of extension agents and their perception of mobile phone usage. The recommendation is that formal integration of mobile phone into extension activities be done to enhance wider coverage, reduce cost and risks associated with movement. Extension agents and farmers need more training on effective usage of SMS and phone calls for interaction on farm related issues. Enforcement of existing telecommunication laws could reduce network failure and also enhance effective usage.
\end{abstract}

Keywords Perception, Communication, Mobile Phone, Short Message Service

\section{Introduction}

Communication has been a veritable tool in all aspects of human endeavours such that it is an indispensable tool that links individuals, organisations and nations. The world is a global village because communication network has closed every gap such that connectivity within the globe is done within seconds using network of information communication technology.

Asemah el al (2017), described communication as the process through which individuals or group of individuals exchange ideas, information, messages, feelings and notions through previously agreed symbols, in order to influence one another. In agricultural extension, communication using various devices and channels has become the effective means of technology transfer. The cycle of research - extension - farmer linkage is only feasible as the innovations are communicated in understandable manner. Communication in agriculture is peculiar and audience specified because it basically involves technical and economic information relating to agriculture.

Agricultural communication is a specialised process of information sharing relating to agricultural production processing and marketing. It is a professionalised information exchange through which stakeholders in agricultural value chain interact. The policy makers, researchers, extension professionals, producers and marketers creatively interact to solve agricultural problem using communication skills and methodologies.

According to Yahaya (2003), it is tempting to use mass media product advertising techniques to sell new agricultural practises as if they were soft drinks or soap. In agriculture it is much different, complex and highly interrelated as it involves innovations to many segments of the population.

The agricultural communicator must present issues and problems from the farmer's orientation using specialised vocabulary to ensure effective communication.

Technology is in every aspect of development because communication is relevant in every human action as a basic tool for interaction. It is currently used to interlink information technology devices like personal computers 
with the use of communication gadgets like telephones and other telecommunication networks.

The role of technology in development globally is a great asset as a result of ever increasing population the emergence needs of human which is due to various challenges of war, insurgence, famine, disease outbreak and various effects of climatic change.

In agriculture technology has been a booster because it replaces the manual labour with technology driven gadgets which ease operations, reduces cost and increases land area under cultivation. Lynch (2018) opined that technology has been acclaimed as the answer to agricultural transformation with its potential as an aid to increase farming efficiency, resilience and yields while maximising costs. Several initiatives are springing up to introduce various information communication devices to facilitate agribusiness

Dookie (2018) reported Revofarm activities. It is a Jamaican Short Message Service and web-based application leading the way in providing weather and agronomic data to farmers on their phones and empowering them to make smart field-level decisions. It was observed that over 200,000 farmers registered in Jamaica lived in poverty and were unable to break even. In 2014, annual agricultural production declined by $30 \%$ after months of extreme drought and bush fires and this propelled Ricardo Cowdie the initiator of Revofarm, such that the objective of his organisation focused on reducing the devastating effect of the disaster. The focus was majorly to reduce the impacts of climate change on crop production thus reducing poverty.

In Ethiopia blueMoon is a youth agribusiness incubator that guides start-ups towards sustainable growth. African Agribusiness Incubators Network, the Entrepreneurship Program for Innovation in the Caribbean and Technical Centre for Agricultural and Rural Cooperation (CTA) Pitch Agrittack are also involved in information communication technology promotion for young entrepreneurs.

Globally, $92 \%$ of internet users access the web via mobile devices and $81 \%$ of Africa's population has subscriptions while $29 \%$ are active internet users (Hootsuite 2018)

The use of mobile phones is widespread in Nigeria such that it has become indispensable in all categories of business and interactions both in the rural and urban settings. The introduction of Electronic Wallet System in Nigeria in 2011 led to a breakthrough in farm input distribution to farmers. The system basically depended on the use of mobile phones, according to Adesina (2015) vouchers for subsidised inputs; seeds and fertilizers were programmed to be received on farmers' mobile phones to buy inputs directly from the agro-dealers such that 20 million smallholder farmers were reached.

Chatel (2018), asserted that mobile phones will be essential in agriculture because future farmers will not necessarily be born into farming families. They will be more likely to become farmers with greater opportunities to learn the trade and adapt their knowledge and skills to address new challenges. It was further reported that (GSMA) Global System for Mobile Association projected that the number of mobile phone subscribers in sub-Sahara Africa should grow from 420 million to 535 million between 2016 and 2020 with $40 \%$ of them having internet access.

Information communication technology is becoming trail blazer in every aspect of economy globally because it enhances information exchange such that information transfer is done faster and cheaper than it has ever been.

\subsection{Communication Channels in Extension}

The various existing communication channels have been employed in agricultural extension as a means of transmitting information between the sender and the receiver. According to Torimiro and Alfred (2008), information is transmitted over a channel that links the sender and the receiver. Messages may be oral, written or verbal and they could be transferred through electronic, print, surface mail and information communication technology including mobile phones.

The Global System of Mobile, Internet, computers, digital radios etc are information communication technology devices that are currently being employed all over the world to promote agricultural development by all stakeholders, farmers, agro input and output marketers, extension professionals, researchers, policy makers etc. The mobile based technology have the potential to deliver to every farmer who has a phone, farm innovation that will be relevant to help adopt the new technology anytime (Ajala 2015)

\section{Methodology}

The study was carried out in Ovia North East and Ovia South West Local Government areas (Edo South agro ecological zone) of Edo State, Nigeria

The area of study is located between longitude $05^{0} 04^{\prime}$ North and $06^{\circ} 43^{\prime}$ East and Latitude $05^{\circ} 44^{\prime}$ latitude. It is bounded in the North by Kogi State and Delta State by the South; Ondo State by the West and Anambra by the East. The State is made up of eighteen Local Government Areas and has a land mass of $19819 \mathrm{~km}^{2}$ with a population of $3,233,366$ persons and population density of 163.14 (NNPC 2006).

The study area (Ovia North East and Ovia South West Local Government areas) are made up of twelve and nine communities respectively and the study covered the Extension Agents working with farmers in the area. sixty extension workers were randomly selected for sampling but only fifty-one respondents were surveyed and used for the analysis. 
Purposive sampling technique was used to select two local government areas from the seven local government areas constituting Edo South Agro-ecological zone because of their peculiarity as predominantly agrarian communities.

\subsection{Measurement of Variables}

The measurement of variables was done taking socioeconomic characteristics of the respondents, frequency of contact with farmers, Global System Mobile features considered appropriate for information dissemination and respondents' perception of the efficiency of mobile phones usage in dissemination of agricultural information using 5-point rating scale. Pearson Product Moment Correlation was used to test the hypothesis.

\section{Results and Discussion}

The socio-economic survey indicated that majority $(72.5 \%)$ of the respondents was male extension agents and $54.5 \%$ were above 45 years old while $90.2 \%$ were married. This indicated that they were adults with family and dependants as shown in Table 1 below. The majority possessed Ordinary and Higher Diploma (84.3\%) while 2\% are holders of Bachelor degree.

Table 1. Respondents' Socioeconomic characteristics

\begin{tabular}{|l|l|l|l|}
\hline Gender & Frequency & $\%$ & \\
\hline Male & 37 & 72.5 & \\
\hline Female & 14 & 27.5 & \\
\hline Total & 15 & 100 & \\
\hline Age (Years) & & & \multirow{2}{*}{ Mean(Yrs) } \\
\hline $25-35$ & 4 & 7.8 & \\
\hline $36-45$ & 19 & 37.3 & \multirow{2}{*}{44.7} \\
\hline$>45$ & 28 & 54.9 & \\
\hline Total & 51 & 100 & \\
\hline Education & & & \\
\hline Secondary & 5 & 9.8 & \\
\hline OND/HND & 43 & 84.3 & \\
\hline Bachelor Degree & 1 & 2.0 & \\
\hline MSc/PhD & 2 & 3.9 & \\
\hline Total & 51 & 100 & \\
\hline
\end{tabular}

Source: Field Survey 2017

Most of the extension agents have 16 years working experience and above thus putting them in the right condition to share agricultural knowledge.

Table 3 shows that $92.2 \%$ of the respondents visited the farmers fortnightly and the practise conform to the peculiarity of Training and Visit extension system used by Agricultural Development Projects as designed by Benor et al (1984). Those whose visits were monthly and occasional constituted $5.9 \%$ and $2 \%$ respectively.

Table 2. Working Experience

\begin{tabular}{|c|c|c|c|}
\hline Working Experience (yrs) & Frequency & $\%$ & Mean \\
\hline 6 & 1 & 2 & \multirow{5}{*}{14.61} \\
\hline $6-10$ & 5 & 9.8 & \\
\hline $11-16$ & 5 & 9.8 & \\
\hline $16-20$ & 30 & 58.8 & \\
\hline$>20$ & 10 & 19.6 & \\
\hline Total & 51 & 100 & \\
\hline
\end{tabular}

Source: Field Survey 2017

Table 3. Respondents' Frequency of Visit to Farmer

\begin{tabular}{|l|l|l|}
\hline Variables & Frequency & $\%$ \\
\hline Once a month & 3 & 5.9 \\
\hline Fortnightly & 47 & 92.2 \\
\hline Occasionally & 1 & 2 \\
\hline Total & 51 & 100 \\
\hline
\end{tabular}

Source: Field Survey 2017

The Mobile Phone features were found to be appropriate for usage based on the survey as shown in Table 4 below was phone calls $(X=4.80)$ and Short Message Service $(X=$ 4.47).This situation confirms the reality in Nigeria where majority of users are familiar with the use of these two features particularly in the suburban where farmers dwell. The peculiar feature of handsets used and the level of farmers' education may also account for this.

This finding agrees with the activities of Sygenta under the program eShamba which disseminated training and advice on good farming practises using text messages to reach 230,000 young farmers in Kenya and Tanzania with results of farmers increase in crop yields of $50 \%$ and $125 \%$ return on investment (Chatel, 2018).

Table 4. Respondents" perception of GSM:

\begin{tabular}{|c|c|c|}
\hline Variables & Mean & Std Deviation \\
\hline Phone calls & $4.80^{*}$ & 0.4 \\
\hline SMS & 4.47 & 0.61 \\
\hline MMS Message & 1.98 & 0.81 \\
\hline Voice Message & 1.59 & 0.96 \\
\hline
\end{tabular}

Source: Field Survey 2017

Respondents indicated that mobile phones facilitate the dissemination of agricultural information to farmers $(X=$ 4.25) thus reducing personal contact with farmers $(X=$ 4.10 ) with the associating risks and costs of frequent visits. The extension agents also revealed the need for training in use of mobile phone to package agricultural information (X $=3.37$ ) such that farmers will be able to understand the messages.

The Table 6 below shows a positive correlation between respondents' work experience $(\mathrm{r}=0.38 ; \mathrm{p}<0.05)$ and their 
perception of mobile phone usage.

Table 5. Respondents' perception of the efficiency of mobile phone usage for agricultural information dissemination

\begin{tabular}{|l|l|l|}
\hline Perception statement & Mean & $\begin{array}{l}\text { Std } \\
\text { Deviation }\end{array}$ \\
\hline $\begin{array}{l}\text { Facilitate agricultural information } \\
\text { dissemination }\end{array}$ & $4.25^{*}$ & 0.74 \\
\hline Reduces personal contact with farmers & $4.10^{*}$ & 0.92 \\
\hline Misinformation may occur & $3.67^{*}$ & 1.01 \\
\hline $\begin{array}{l}\text { Extension agents are trained on mobile } \\
\text { phone usage }\end{array}$ & $3.45^{*}$ & 1.38 \\
\hline Farmers understand the messages & $3.37^{*}$ & 0.97 \\
\hline $\begin{array}{l}\text { Network problem will not limit usage for } \\
\text { extension }\end{array}$ & $3.24^{*}$ & 1.21 \\
\hline $\begin{array}{l}\text { Mobile phone can be used to transfer } \\
\text { technical and economic agricultural } \\
\text { information }\end{array}$ & $3.14^{*}$ & 1.11 \\
\hline Erratic power supply will not limit usage & $3.08^{*}$ & 1.16 \\
\hline $\begin{array}{l}\text { Information can be sent easily through } \\
\text { SMS. MMS, Voice Message }\end{array}$ & 2.78 & 1.22 \\
\hline $\begin{array}{l}\text { Govt policy exist concerning mobile phone } \\
\text { usage for information dissemination to } \\
\text { farmers }\end{array}$ & 2.44 & 1.22 \\
\hline Many farmers can operate mobile phone & 2.33 & 1.03 \\
\hline Many farmers lack personal mobile phones & 2.27 & 0.98 \\
\hline $\begin{array}{l}\text { Mobile phone network exist in many rural } \\
\text { areas }\end{array}$ & 2.24 & 1.03 \\
\hline $\begin{array}{l}\text { Mobile phones can be misplaced easily by } \\
\text { farmers }\end{array}$ & 2.08 & 1.18 \\
\hline $\begin{array}{l}\text { Mobile phone is not an expensive } \\
\text { information dissemination medium }\end{array}$ & 1.25 & 0.44 \\
\hline Aged(Megn> 3.00) & \\
\hline
\end{tabular}

Agreed( Mean > 3.00)

Source: Field Survey 2017

Table 6. Relationship between respondents' socioeconomic characteristics and perception of mobile phone usage

\begin{tabular}{|l|l|l|}
\hline Variable & Correlation coefficient $(\mathrm{r})$ & P level \\
\hline Age & -0.28 & 0.846 \\
\hline Gender & 0.194 & 0.173 \\
\hline Marital status & 0.159 & - \\
\hline Family size & 0.145 & 0.312 \\
\hline Education & 0.049 & 0.734 \\
\hline Working experience & $0.384^{*}$ & 0.005 \\
\hline Contact with farmers & 0.047 & 0.743 \\
\hline
\end{tabular}

Significant at $5 \%$ level

Source: Field Survey, 2017

\section{Conclusions}

This study shows that Mobile phone as a communication device facilitates agricultural information transfer in the area of study as perceived by the extension agents, majority of whom were well experienced in agricultural extension work, had experience of over sixteen years. Majority of the extension agents $(90 \%)$ visited farmers fortnightly as expected. The use of Mobile phones was perceived as appropriate for transfer of agricultural information using the phone call and Short Message Service (SMS) and this reduced frequency of visits and associated costs and risks involved in movement.

Training and retraining of extension workers to ensure proper coding of messages without distortion become necessary as revealed in the study. It was also discovered that farmers were able to understand the messages relayed through mobile phones since the extension agents were trained professionals and were able to communicate with the farmers in an understandable dialect or language.

\section{Recommendations}

The use of Mobile phones should be formally integrated as a core communication device in agricultural extension work by all the stakeholders involved in extension farmers linkage to ensure wider outreach per time and cost reduction.

The major telecommunication service providers should be mobilized to install infrastructure in rural settlements with effective control to ensure regularity of network flow.

There should be introduction of training opportunities for farmers and extension agents on the technicalities of using Mobile phones in extension work so as to understand the peculiarities of coding agricultural information.

Software applications suitable for use in emergency cases to meet current needs in agriculture such as climate change and pests/diseases outbreak should be developed. Though the challenge of network failure may pose a problem, maximum advantage should be taken when the network is good.

\section{REFERENCES}

[1] Adesina, A. A., (2015). Riding the Wave of Reformation. In Technical Centre for Agricultural and Rural Cooperation, Wageningen, The Netherlands.(CTA) Spore No 176 P.7

[2] Ajala, I., (2005). GIS and GSM Network Monitoring: A Nigerian Case Study" Directions Magazine. Retrived 18/7/2017 from http://www.directionsmag.com/articles/gis -and-gsm-.network-quality-monitoring-a-nigerian-case-stu dy/123278

[3] .Asemah, E. S; Nwammuo A. N. and Adeline, O.A.N., (2017). General Introduction. In Theories and Models of Communication. Jos University Press, Jos, Plateau state, Nigeria. P.1

[4] Benor, D., Harrison, J. Q. and Baxter, M., (1984). Agricultural Extension: The Training and Visit System. Pub. International Bank for Reconstruction and Development: The World Bank, Washington D.C. P.36 
[5] Chatel, B., (2018). Next Generation Farmers: Digitally Connected and Business Minded. In Technical Centre for Agricultural and Rural Cooperation, Wageningen, The Netherlands. (CTA) Spore No 187 Pp4-6.

[6] Dookie S. (2018). ICT start-ups for crop production and marketing In Technical Centre for Agricultural and Rural Cooperation, Wageningen, The Netherlands. ( CTA) Spore № 189 P.27.

[7] HootSuite (2018) Technical Centre for Agricultural and Rural Cooperation, Wageningen, The Netherlands. ( CTA) Spore № 189 P. 20

[8] Iroko, M., (2012). Federal Government abandons \$200M Rural Telephony Project Zinbio Inc. Retrieved July 22, 2017. http://www.zimbio.com/Nigeria/articles/GniWJ99uc $\mathrm{zp} / \mathrm{FG}+\mathrm{ABANDONS}+200 \mathrm{M}+\mathrm{RURA}+\mathrm{TELEPHONY}+\mathrm{PR}$ OJECT

[9] Lynch S. (2018). Developing a winning strategy in CTA Spore № 189 P. 18.

[10] National Population Commission (2006): National Population Commission Diary: Issues on 2006 Census, National Population Commission Abuja.

[11] Torimiro, D. O. and Alfred, Y.(2008). Communication in Agricultural extension In Akinyemiju, O. A. and Torimiro, D.O. (eds) Agricultural Extension; A Comprehensive Treatise. Pub. ABC Agricultural Systems Ltd Lagos, Nigeria.P.135.

[12] Yahaya, M. K., (2003). Development Communication: Lessons for Change and Social Engineering Projects. Corporate Graphics Ltd. Ibadan. P.84 